\title{
THE USE OF AHP IN SUSTAINABLE FOREST MANAGEMENT CERTIFICATION
}

\author{
Mubariq Achmad \\ The Indonesian Eco-labeling Institute \\ Menara Era Suite 703 \\ Jl. Senen Raya 135-137, Jakarta 10410, Indonesia \\ Mubariqa@cbn.net.id \\ Kirti Peniwati \\ PPM Graduate School of Management \\ Jl. Menteng Raya 9 Jakarta 10340, Indonesia \\ Kirti@cabi.net.id
}

\begin{abstract}
Sustainable forest management (SFM) certification is a process to determine whether a forest management unit or company has been operating and performing at the acceptable degree of sustainability. The Indonesian Eco-labeling Institute (LEI) has been establishing a certification system using the AHP's absolute measurement approach. The model is a seven level tree-hierarchy with 146 indicators. The indicators were determined and prioritized with respect to three criteria of sustainability: forest resource/production sustainability, forest ecological function sustainability, and forest social function sustainability. A company is assessed and evaluated on each and every indicator to accumulate a composite grade, and is certified if the grade is higher than the minimum standard. The recommendation is made by an eight-member expert panel .
\end{abstract}

\section{Introduction}

Sustainable forest management (SFM) certification is a process to determine whether a forest management unit or company has been operating and performing at the acceptable degree of sustainability. The decision to be made is whether to certify or not to certify a forest management unit. The recommendation for decision has to be made by an eight-member expert panel. A company is certified if it passes the minimum requirements of sustainability as reflected by a composite grade. The composite grade is a number to be obtained through the application of AHP on 146 indicator values arranged in certain hierarchical format. Sustainability criteria and management dimensions serve as basis for developing the indicators. The use of AHP [Saaty, 1990] in the process of making recommendation for decision is believed to have the following benefits: first, to fulfil the need for a credible decision making process through an objective, systematic and traceable tool; and second, to minimize the personal and subject dominance in this multiple criteria decision making process.

The purpose of this paper is to present the AHP model of the SFM and the certification process. The system has been documented in a guidance for decision making, issued by the Indonesian Eco-labeling Institute (LEI), and called Pedoman BSN 99-24. The structure of the model, data collection, and evaluation process is discussed followed by a short history of development of the system is explained. We also describe the problems and difficulties faced by the users of the model and AHP as a decision making tool. We concludes this short paper with some remarks for future improvement of the application of AHP for SFM Certification. 


\section{Structure of the Model, Data Collection and Evaluation Process}

The AHP model for SFM certification decision making consists of the following seven level hierarchy:

1) SFM as a goal;

2) Performance criteria of SFM that consists of three components: forest resource/production sustainability, forest ecological function sustainability, and forest social function sustainability.

3) Sub-criteria of SFM for each components. Resource/production criterion has three sub-criteria; ecological criterion has two sub-criteria; social criterion has two sub-criteria.

4) Achievement of sub-criteria at three aggregate categories of management efforts: Territorial/Area management, Forest management, and Institution management.

5) Achievement of sub-criteria at the sub-categories of each aggregate management efforts. Each of management categories has three sub-categories of management activities.

6) Indicators of sub-criteria at each sub-categories of management efforts. Indicators are defined as the relevance or relationship between performance sub-criteria and the sub-category of management activities in which it intersects. Some intersections contain more than one indicator. Wherever irrelevant, there is no indicator at the intersection. Information on the indicators are collected at its verifier level.

7) Intensity ratings (verifiers) located at the bottom level of the hierarchy. They are determined and defined for each indicator such that unit performance can be measured against each and every indicator.

In its original presentation format, the indicators are arranged in the matrix form instead of a decision tree. The criteria and the sub-criteria serve as the $\mathrm{X}$-axis, and the management efforts/activities and its subcategories serve as the $\mathrm{Y}$-axis. The advantage of this presentation format is that the matrix will serve as a score card when field evaluation is completed. By looking at 'the card' the company can tell directly what aspect of management it needs to improve in order to increase the weakly performing indicators.

For the use in AHP, the model is structured in a decision tree as shown in the appendix. The decision tree describes the complete structure of indicators for one of the sixth-level nodes below the goal. The rest of the indicators underneath the sixth-level nodes are given in the table following the decision tree.

The field data for the verifiers are collected by a separate team of professional field assessors. Prior to field assessment, the first expert panel decides whether the certification process worth continuing to the field assessment stage after evaluating the documents of the forest management that applies for certification. The assessors report the information regarding each and every indicator, and present it to a second expert panel for evaluation. For each and every indicator, the second expert panel studies the information, judges which definition of the intensities best fits the information, and assign the intensity that corresponds to the definition to represent the expert's evaluation regarding the performance of the unit in that particular indicator. The panel then makes recommendation for decision (although in this paper it is generally refereed to as decision), after the evaluations for all indicators have been imputed through the AHP model, based on the synthesized overall score generated by the AHP's supporting software, Expert Choice. In addition to decision recommendation, the expert panel makes technical recommendation to improve the company performance based-on the weight or the significance of contribution of indicators in the overall score in the AHP structure.

\section{Brief History and Challenges in Developing AHP Model for SFM Certification}

The nature of the decision making process that involves multiple criteria and multiple decision makers requires a decision instruments that can minimize domination by subject/criteria of the decision as well as by individual decision maker. Traceability and consistency across criteria or decision framework are other important features of the decision-making problem for SFM certification. These are key reasons behind the choice to use AHP in SFM certification.

The AHP model for SFM Certification was first developed in 1996 by LEl's expert team, assisted by two external experts who have used AHP for other applications. The first version of the model was developed 
even before the indicators of sustainable forest management had been finalized. The first challenge in developing this model is to familiarize the AHP concept to the potential users of the model, i.e. the Indonesian forestry expert communities. One criticism against the use of AHP is that it could potentially undermine the principle of maximum transparency that LEI is trying to promote if the model is seen as complicated and not easy to communicate. A try-out was attempted using a data set resulted from the tryout of the criteria and indicators on one forest concessionaire. Although no documented result reported from the try-out of the AHP model, the experts convinced that the AHP model can be used as the decision tool for SFM certification. The finishing stage of the model was postponed until the criteria and indicators as well as the whole certification procedures were finalized.

Prior to finalizing the proposed certification system, the whole system was reviewed by four independent experts each looking at the whole system but emphasizing his/her own field. One AHP expert is included in this review team. The AHP expert (and prior to this, the LEI's expert team itself) found a couple of problems in the proposed AHP model. The main problems encountered are:

a. The value resulted from the AHP process was not sensitive to the changing value of the indicators;

b. The forestry experts were not sure how to calculate the composite value, whether horizontally or vertically, given that the indicators were arranged in a matrix form. Through a series of intensive discussions, both problems were overcome after the AHP expert insisted that the LEI's experts write down how the criteria and indicators should be read, and how each level of the hierarchy explains the criteria at the level right above it;

c. The values used to indicate level of performance (i.e. very bad to excellent) were not well defined at the indicator level; and as a result,

d. Potentially, it is difficult to maintain consistency across different panels (i.e. across different concessionaire evaluations) in the determination of 'distance' when conducting pair-wise comparison.

The first and second problems were solved at once prior to the actual implementation of the model after the experts agreed on the way the indicators or criteria should be read at each level of hierarchy in explaining the level above it. However, the difficulties induced by problems $\mathrm{c}$ and $\mathrm{d}$ were passed on to the real implementation stage due to the failure to specify the specific value range defining each intensity rating of an indicator prior to implementation. It has been realized that, at this stage, it is difficult to determine and define intensity ratings to satisfy the following conditions:

- They cover the whole range of the possible performance of units being evaluated.

- They differentiate the units to be evaluated effectively in terms of their performance on each indicator.

\section{Challenges in Implementation}

At the time of this writing, there are two forest concessionaires that have been evaluated by different sets of evaluators. In addition to the problems related to the 'readiness' of the model mentioned above, the main problem faced is in educating the members of expert panel on the use of AHP concept for making the certification decision. Although LEI does not require the members of the expert panel to master the AHP method, as experts, most of them demand a significant understanding on how their evaluation will be framed under AHP method to generate a single composite value. Socialization of the idea in several forums in the past, plus a briefing on the concept before the panel start working, do not seem very effective in getting the experts tuned to its application. In both cases, LEI provided a facilitator (although not specifically designated for the task) to help guide the AHP process. Lack of training materials for the expert panel members, and lack of especially designated facilitators pose their own challenge in the implementation of AHP for SFM certification.

The decision to pass or fail a forest concessionaire in the SFM certification process depends also on the standard or passing threshold value. The main challenge here is that in forest certification context, such value is not available because SFM forest certification is a relatively new concept. The initiative itself has only been around for ten years. The unavailability of standards has induced another creativity in the use of AHP, i.e., to generate a passing grade or threshold value to be used as standard for certification based on the perceived typology of the forest under evaluation. The dilemma here is that without having 
the standard, one should evaluate the units in relative terms. However, the big number of units to be evaluated, and the fact that they cannot be evaluated at once, give no choice but use the absolute measurement mode of the AHP.

Under LEI's SFM certification system, Indonesia's tropical forest lands are categorized into four types based on some characteristics of environmental and social functions of the forest under evaluation. Eventually, there will be one uniform standard for each type of forest based on the principles in the typology. The type of the forest is identified by the first expert panel prior to field assessment. Field assessors verify and submit descriptions on the actual field conditions. The second expert panel makes the standard for that particular concessionaire using AHP based on this information. The standard is made before the expert panel assigns value for each indicators. In creating the standard or passing grade for the concession under evaluation, the expert panel asks themselves the question: "Given the typology of this forest, for indicator $x$, what is acceptable level of performance (i.e. fair/good/very good, etc.) for sustainability for this particular forest management unit?" Answers generated for each of the indicators will then be imputed into the AHP to generate a composite 'standard of sustainability acceptance' for that particular concessionaire. Over the long-run, LEI expects that standards from similar concessionaires can be converged into a single standard for each typology of the production forests.

Using typology of forests also creates another complication in determining the maximum value for each indicator. The choices are between 'giving the same score (say 10) for top performance level for all types of forests and consequently, having mutually exclusive among the typology' or 'having a different maximum score for each type of forest to reflect different level of difficulties in achieving top performance level across types'. The experts chose the first option.

\section{Concluding Remarks}

Application of AHP for sustainable forest management certification is clearly an academically challenging and rewarding exercise. It works! And it will work better if the following obstacles can be eliminated:

a. Simple and easy way to communicate the AHP concept to the general public needs to be developed. Image of complexity do not seem to go hand in hand with the strong intention for maximum transparency and traceability of certification result.

b. More effective training materials for expert panel members also need to be developed. Expert panel feels more comfortable if they could follow the tool that frame the results of their evaluation.

c. The existing structure of the model seems to be complex, probably due to too many indicators involved. Since LEI's criteria and indicators of sustainable forest management is now under revision, it is expected that fewer indicators would also lead to more efficient structure of the AHP model.

\section{References}

Lembaga Ekolabel Indonesia (LEI), Pedoman BSN 99-24, Pedoman Pengambilan Keputusan Program Sertifikasi Pengelolaan Hutan Alam Produksi Lestari.

Saaty, T.L. (1990). The Analytic Hierarchy Process: Planning, Priority Setting, Resource Allocation. RWS Publication, Pittsburgh, PA. 